Article

\title{
Impact of Inoculum Type on the Microbial Community and Power Performance of Urine-Fed Microbial Fuel Cells
}

\author{
Maria Jose Salar-Garcia ${ }^{1, *}$, Oluwatosin Obata ${ }^{1}$, Halil Kurt ${ }^{2} \odot$, Kartik Chandran ${ }^{2}$, \\ John Greenman ${ }^{1}\left(\mathbb{D}\right.$ and Ioannis A. Ieropoulos ${ }^{1, * \mathbb{D}}$ \\ 1 Bristol BioEnergy Centre, Bristol Robotics Laboratory, University of the West of England \\ Bristol BS16 1QY, UK; Oluwatosin.Obata@newcastle.ac.uk (O.O.); john.greenman@uwe.ac.uk (J.G.) \\ 2 Department of Earth and Environmental Engineering, Columbia University, New York, NY 10027, USA; \\ peziza@yahoo.com (H.K.); kc2288@columbia.edu (K.C.) \\ * Correspondence: mariajose.salar@upct.es (M.J.S.-G.); ioannis.ieropoulos@brl.ac.uk (I.A.I.)
}

Received: 15 October 2020; Accepted: 13 November 2020; Published: 3 December 2020

\begin{abstract}
Bacteria are the driving force of the microbial fuel cell (MFC) technology, which benefits from their natural ability to degrade organic matter and generate electricity. The development of an efficient anodic biofilm has a significant impact on the power performance of this technology so it is essential to understand the effects of the inoculum nature on the anodic bacterial diversity and establish its relationship with the power performance of the system. Thus, this work aims at analysing the impact of 3 different types of inoculum: (i) stored urine, (ii) sludge and (iii) effluent from a working MFC, on the microbial community of the anodic biofilm and therefore on the power performance of urine-fed ceramic MFCs. The results showed that MFCs inoculated with sludge outperformed the rest and reached a maximum power output of $40.38 \mathrm{~mW} \cdot \mathrm{m}^{-2}$ anode $(1.21 \mathrm{~mW})$. The power performance of these systems increased over time whereas the power output by MFCs inoculated either with stored urine or effluent decreased after day 30 . These results are directly related to the establishment and adaptation of the microbial community on the anode during the assay. Results showed the direct relationship between the bacterial community composition, originating from the different inocula, and power generation within the MFCs.
\end{abstract}

Keywords: microbial fuel cell; urine; inoculation method; electroactive bacteria; bioenergy

\section{Introduction}

The effects of global warming on everyday life, along with the fossil fuel depletion have fuelled the search for alternative, clean energy technologies. Microbial fuel cells (MFCs) emerge as an environmentally friendly technology where bacteria drive the electricity production from the chemical energy stored in a specific substrate [1,2]. These devices consist of an anodic compartment, where bacteria degrade the organic matter, releasing cations, electrons and other metabolic by-products; this half-cell is physically separated from the cathode chamber, by a semi-permeable membrane. Electrons flow from the anode, through an external circuit, to the cathode, where they recombine with the incoming cations (e.g., protons diffusing through the semi-permeable membrane) to complete the reaction and close the circuit. While in the anodic chamber, oxidation of the organic matter takes place, in the cathode an oxidant, e.g., oxygen, is reduced to produce water. However, the oxygen reduction reaction (ORR) on the cathode is one of the limiting factors of this technology because of the need for a catalyst to accelerate the process [3,4]. So far, great efforts have been made in terms of material science to find a suitable catalyst, which balances high catalytic activity, good long-term stability and low cost [5-9]. Platinum group metals (PGMs) are widely used due to their high catalytic 
activity. However, their high cost and poisoning limitations make them unsuitable for use in scaled-up systems. Carbonaceous materials such as activated carbon or metal-free catalysts represent a real alternative to PGMs due to their low cost and longevity, which enable real-world implementation of this technology $[8,10,11]$.

In addition to the advancements in designing new and efficient catalysts, the modification of the anode surface has been reported as a suitable way to improve the energy generation from MFCs. Activated carbon is a cost-effective material that increases the specific surface area, which facilitates bacterial attachment and development of a viable electroactive biofilm [12]. Other materials as well as techniques have also resulted in increasing specific anode area and consequently the power performance of the MFCs. One of these techniques is the modification of the anode with a wide variety of conductive polymers such as polyaniline (PANI) [13], polypyrrole (PPy) [14] or poly(3,4-ethylenedioxythiophene)-polystyrenesulfonate (PEDOT-PSS) [15].

Another important element of MFCs is the membrane, which separates the anode and the cathode. Commercial polymer-based membranes, e.g., Nafion or Ultrex, have been commonly used due to their high ionic conductivity and good performance. However, their high cost and moderate long-term performance have steered research into low-cost alternatives, which enable the commercialisation of MFCs [16]. Ceramics represent a broad range of materials with meaningful advantages over conventional polymer-based membranes, for instance, their natural availability, cost-effectiveness and robustness, which reduces the maintenance needed in potential scaled-up systems [17,18]. The recent use of MFCs in remote location opts for low-cost materials with low environmental impact. Another benefit of using ceramic materials is that their properties, such as porosity or ionic conductivity, can be tailored by changing the kilning temperature or doping the raw material [19-21].

One of the unique advantages of MFCs is the use of different types of waste as feedstock for microbes, whereby contaminants are broken down for the production of electricity [22,23]. So far, a wide range of waste materials have been used as substrates, e.g., waste from the brewery, dairy or oil refinery industries, food processing wastewater and domestic wastewater, among others [24-26]. More recently, the use of neat urine as feedstock in different kinds of bioelectrochemical systems has gained a lot of interest due to its abundance, buffering capacity and high chemical oxygen demand [27-29]. This natural waste product has been successfully used for ammonium recovery, powering lights, charging smartphones or powering a microcomputer through MFCs [30,31]. For MFCs, it is well known that the concentration, organic matter loading and bacterial diversity of the inoculum as well as feedstock, affect the power performance. The use of complex substrates with high organic loading usually helps in stablishing a diverse and electrochemically active microbial community on the anode. The feed-rate and shear-stress are also important parameters that need to be optimised in continuously fed systems, as is the temperature, since all these can affect the behaviour of the anodic microbial communities. In terms of $\mathrm{pH}$ stability, it is important to use a feedstock with natural buffering capacity, such as urine, in order to avoid adding external $\mathrm{pH}$ buffer solutions, which increases cost and complicates maintenance. Thus, the choice of an appropriate inoculum and suitable operating conditions, significantly influences the performance of MFCs [32,33].

At present, research is focused on moving the MFC technology from the laboratory to the field. The real implementation of this technology still poses a challenge especially when the deployment takes place in rural places with low or limited development. As the anodic biofilm dictates power output, it is vital to understand the ecological behaviour of the anodic microbial community under different operating conditions [34]. The influence of factors such as the substrate [35,36], external resistance [37] or anode materials [38], on the microbial community have already been reported. According to previous work, the variation of the operating conditions, substrate or electrode materials strongly affects the anodic microbial community and, therefore, the power performance of MFCs. In order to promote the real implementation of this technology, it is important to explore the behaviour of the microbial diversity under different operating conditions, especially in the start-up phase, which still poses a challenge for the functioning of the system. 
The enrichment of the bacterial community of the anodic biofilm is a strong indication of process functionality. However, despite the plethora of bacteria present in MFCs, only those that are capable of electroactive metabolism would directly contribute to electricity generation. As such, bacterial population or diversity increases in MFCs do not often translate to increased power generation. Nevertheless, a synergistic approach to electricity generation has been reported where different bacterial strains work in symbiosis to bring about the degradation of various contaminants thereby providing the needed substrates for the electroactive strains [36].

According to this approach, this work aims to investigate in-depth the effect of using three different types of inocula based on human urine on the anodic microbial community of MFCs and, therefore, its correlation with the power performance of the overall system. All tests were performed in triplicate with a total number of 9 MFCs run simultaneously in continuous mode for 90 days. The results were analysed in terms of microbial diversity and power output but also stability and functionality for long operating processes.

\section{Materials and Methods}

\subsection{Microbial Fuel Cell (MFC) Set-Up}

MFCs were assembled using $5 \mathrm{~cm}$ tall terracotta cylinders sealed on one side (Orwell Aquatics, UK). The outer diameter was $2.9 \mathrm{~cm}$, the inner diameter was $2.1 \mathrm{~cm}$, so the thickness of the cylinder wall was $4 \mathrm{~mm}$. The anode consisted of a piece of carbon veil (carbon loading $20 \mathrm{~g} \cdot \mathrm{m}^{-2}$ ) of $300 \mathrm{~cm}^{2}$ folded and wrapped around the outside wall of the terracotta cylinder. Nickel chromium wire was used for connecting the electrode to the load and data logging apparatus. The cathode was made of a paste of activated carbon and polytetrafluoroethylene (PTFE) hot pressed over a piece of carbon veil (carbon loading $20 \mathrm{~g} \cdot \mathrm{m}^{-2}$ ) of $30 \mathrm{~cm}^{2}$ [39]. The cathode was placed inside the cylinder and connected to the anode through an external circuit. The cylinder with both electrodes was placed in a plastic container ( $60 \mathrm{~mL}$ working volume) where the outer wall of the terracotta cylinder along with the anode was fully immersed in the anolyte. Anaerobic conditions in the anodic compartment were maintained by using the lid of the plastic container (see Figure 1). A multi-channel data logger (Agilent 34972A, Farnell, UK) was used to continuously monitor the voltage of the systems. The external resistive load was adjusted every 8 days (i.e., whilst maturing) until reaching maximum power, which was achieved across a load of $100 \Omega$; this remained constant until the end of the experiments.

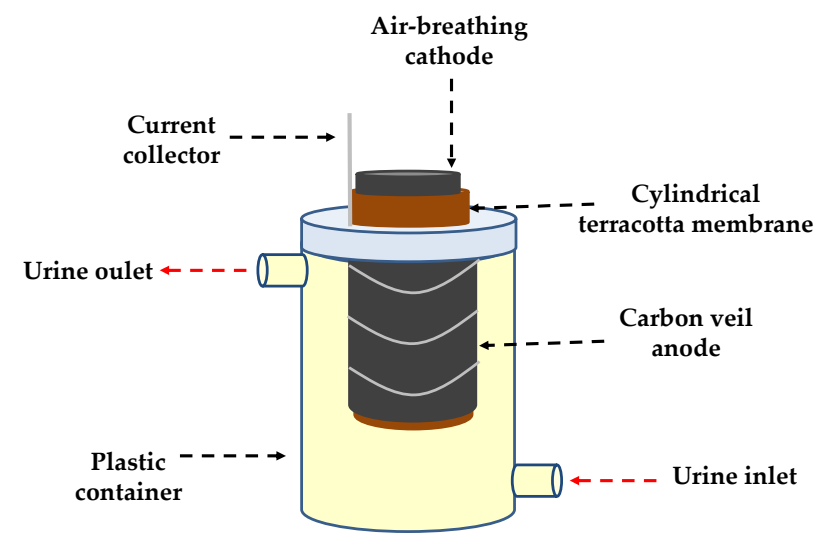

Figure 1. Scheme of the microbial fuel cell (MFC) set-up used in this work.

\subsection{Inoculation Methods}

In this section the procedure employed for each type of inoculum assessed in triplicate is described. All systems were inoculated simultaneously and kept working for 90 days in continuous mode with a total number of 9 MFCs were ran in parallel. 
- Method I: The MFCs were inoculated with naturally hydrolysed human urine. Before collection, urine was stored in a tank for at least $48 \mathrm{~h}$, which allowed the hydrolase enzymes to precipitate struvite, increasing the $\mathrm{pH}$ to 9.3 . The MFC were batch-fed daily for 4 days and then continuously fed with stored urine at a flow rate of $200 \mathrm{~mL} \cdot$ day $^{-1}$.

- Method II: In this case, the systems were inoculated with a mixture containing $1 / 1_{V / V}$ anaerobic sludge collected from a Wessex Water treatment plant (Saltford, UK) and stored urine (pH: 9.28), which was replenished with fresh solution daily for 4 days. After this period, the MFCs were continuously fed with stored urine at a flow rate of $200 \mathrm{~mL} \cdot \mathrm{day}^{-1}$.

- Method III: The last inoculum consisted of using a solution containing $1 / 1_{V / V}$ effluent from a long-term working MFC and stored urine ( $\mathrm{pH}$ : 9.29). The solution was replenished daily with a fresh mixture for 4 days, after which period, the systems were continuously fed with stored urine at a flow rate of $200 \mathrm{~mL} \cdot \mathrm{day}^{-1}$.

\subsection{Electrochemical Characterisation}

The polarisation of the 9-MFCs was performed by using a potentiostat ( $\mu$ AutoLab III/FRA2, Metrohm, The Netherlands) by linear sweep voltammetry (LSV) from open-circuit voltage (OCV) to $0.05 \mathrm{mV}$ at a scan rate of $0.25 \mathrm{mV} \cdot \mathrm{s}^{-1}$. The polarisation of the MFCs was performed 4 times during the experiment: on days 15, 30, 60 and 90; subsequently the external load was kept constant. The measurements were performed at a stable open-circuit voltage in a two-electrode configuration where the cathode is connected to the working electrode, the anode is connected to the counter electrode and the reference channel is short-circuited with the counter electrode channel. Polarisation curves of the 9-MFCs were obtained by plotting the cell voltage versus current (V vs. I) whereas power curves were obtained by plotting power versus current (P vs. I).

For a better understanding of the impact of the inoculum type on the anode performance, the electrodes were individually characterised by LSV in a three-electrode configuration at the same scan rate as with the complete cell. The polarisation of the anode was performed connecting the anode to the working electrode, the cathode to the counter and the reference channel to a $\mathrm{Ag} / \mathrm{AgCl} 3 \mathrm{M} \mathrm{KCl}$ electrode. The measurements were performed between open-circuit potential (OCP) and $-0.1 \mathrm{mV}$ vs. $\mathrm{Ag} / \mathrm{AgCl}$. For the polarisation of the cathode, the cathode was set as the working electrode and the anode as the counter electrode, keeping $\mathrm{Ag} / \mathrm{AgCl} 3 \mathrm{M} \mathrm{KCl}$ as the reference electrode.

\subsection{DNA Isolation, Next-Generation $16 S$ rRNA Amplicon Sequencing and Sequence Data Analysis}

Anodic bacterial community as well as the starting materials (sludge and urine) were collected at regular intervals for DNA analysis (T0, T30, T60 and T90). Metagenomic DNA from samples were extracted in duplicates using Dneasy Blood and Tissue kit (Qiagen, Germantown, MD, USA) according to kit protocol. DNA quality and quantity were measured by Nano-Drop Lite spectrophotometer (Thermo Fisher Scientific, Waltham, MA, USA). Bacterial 16S rRNA gene was amplified using universal primers 1055f (ATGGCTGTCGTCAGCT) and 1392r (ACGGGCGGTGTGTAC) [40] and barcoded fusion primers with sequencing adaptors. Polymerase chain reaction (PCR) runs were carried out in a total $25 \mu \mathrm{L}$ volume containing $0.5 \mu \mathrm{L}$ of forward primer, $0.5 \mu \mathrm{L}$ of reverse primer (10 pmoles $/ \mu \mathrm{L}), 0.1 \mu \mathrm{L}$ of MyTaq polymerase $(5 \mathrm{u} / \mu \mathrm{L}$ ). Other components of the mix are $5 \mu \mathrm{L}$ of PCR buffer (comprising $5 \mathrm{mM}$ dNTPs, $15 \mathrm{mM} \mathrm{MgCl}_{2}$, stabilizers and enhancers), $18.4 \mu \mathrm{L}$ of molecular grade water $(17.4 \mu \mathrm{L})$ and $0.5 \mu \mathrm{L}$ of DNA sample. Negative controls containing $0.5 \mu \mathrm{L}$ of sterile molecular grade water were included in all cases. The PCR reaction was started with initial denaturation at $95^{\circ} \mathrm{C}$ for $3 \mathrm{~min}$, denaturation at $95{ }^{\circ} \mathrm{C}$ for $1 \mathrm{~min}$, annealing at $55^{\circ} \mathrm{C}$ for $1 \mathrm{~min}$ and extension at $72{ }^{\circ} \mathrm{C}$ for $1 \mathrm{~min}$, in a total of 30 cycles [41]. The quality and quantity of the $16 \mathrm{~S}$ amplicon sequence was checked with bioanalyser (Agilent Technologies 2100, Santa Clara, CA, USA). The $16 \mathrm{~S}$ amplicon sequencing was performed using an Ion Torrent PGM (Thermo Fisher, Bedford, MA, USA) platform with Ion Torrent 318v2 Ion Chip by following manufacturer's instructions (Ion PGM Hi-Q Sequencing kit, Thermo Fischer, Bedford, MA, USA). All 16S rRNA gene raw sequences have been deposited to 
Sequence Read Archive (SRA) at the National Center for Biotechnology Information (NCBI) under the accession number SAMN12583022-SAMN12583029. Qiime2 V.2018.11 [42] pipeline was used 16S amplicon data analysis. Quality check and chimera removal of $16 \mathrm{~S}$ amplicon reads were performed dada2 command. Taxonomic classification was performed by consensus-blast command against Silva ribosomal databases v132 [43].

\section{Results}

\subsection{Microbial Fuel Cell Performance}

Before characterising the electrochemical performance of MFCs, the stability of power output was investigated in triplicate for 90 days in continuous mode. As explained in the Materials and Methods section, each triplicate was simultaneously inoculated according to the three methods described above. As shown in Figure 2, the power output of all MFCs from all conditions was quite similar since the anodic biofilm had not been completely formed yet. However, after day 20, the power output levels started varying significantly. From then on, MFCs inoculated with sludge outperformed both the MFCs inoculated with stored urine and those with MFC effluent, reaching a maximum value of $31 \mathrm{~mW} \cdot \mathrm{m}^{-2}$ anode $(0.93 \mathrm{~mW})$. Once the systems reached steady-state, the MFCs inoculated with sludge maintained stable power production between $25 \mathrm{~mW} \cdot \mathrm{m}^{-2}$ anode and $26.7 \mathrm{~mW} \cdot \mathrm{m}^{-2}$ anode $(0.75$ and $0.8 \mathrm{~mW}$ ). The reduction in power observed at certain points was caused by electrical connection artifacts, however the power output completely recovered after these were repaired. In the case of the MFCs inoculated with stored urine and sludge, both triplicates exhibited similar values of power output until day 37, when important differences were observed. From day 37 until day 60, the MFCs inoculated with stored urine outperformed those inoculated with MFC effluent, reaching a maximum value of $18.3 \mathrm{~mW} \cdot \mathrm{m}^{-2}$ anode $(0.55 \mathrm{~mW})$. However, after day 60 the power performance of MFCs inoculated with effluent increased above that from MFCs inoculated with stored urine, reaching a maximum value of $19 \mathrm{~mW} \cdot \mathrm{m}^{-2}$ anode $(0.57 \mathrm{~mW})$. Subsequently, the mean power output by these systems was $17.7 \mathrm{~mW} \cdot \mathrm{m}^{-2}$ anode $(0.53 \mathrm{~mW})$. In the case of the MFCs inoculated with stored urine, the power performance remained stable from day 37 until the end of the investigation. Only a slight reduction in power was observed between days 62 and 65 due to lack of feeding. Once feeding was reinstated, the systems returned to the previous values. These results may be related to differences in the anodic biofilm developed as a result of the different origins. According to the long-term power performance, the use of sludge as bacterial inoculum in urine fed MFCs might promote the development of a more efficient biofilm than using stored urine or effluent from other urine-fed MFCs. When comparing the results obtained using sludge and MFC effluent as inocula, it seems that stored urine reaches steady state faster than those systems inoculated with effluent. However, despite taking longer to adjust, eventually power output was highest. It may be possible that bacteria coming from other MFCs as those contained in the effluent inoculum, need more time to adapt to the new operating conditions but they are able to develop a more efficient biofilm than bacteria present in stored urine.

Figure 3 shows the average electrochemical performance of the overall cells after 15, 30, 60 and 90 days working in continuous mode. According to the long-term power output previously discussed, the maximum value was reached by MFCs inoculated with sludge. It was also observed than this value increased over time, reaching a maximum of $40.38 \mathrm{~mW} \cdot \mathrm{m}^{-2}$ anode $(1.21 \mathrm{~mW})$ after 90 days. These results are in line with the electrochemical characterisation of the individual electrodes shown in Figure 4, which shows how the anode of the MFCs inoculated with sludge improved its performance over time (see Figure 4D). By contrast, the maximum power output reached by the MFCs inoculated either with stored urine or effluent decreased over time, reaching in both cases the maximum value in the polarisation on day 30. After 30 days, the MFCs inoculated with stored urine produced a maximum power of $29.64 \mathrm{~mW} \cdot \mathrm{m}^{-2}$ anode $(0.89 \mathrm{~mW})$, which then decreased by $29 \%$ and thereon remained stable until the end $\left(21.04 \mathrm{~mW} \cdot \mathrm{m}^{-2}\right.$ anode $\left.-0.63 \mathrm{~mW}\right)$. A similar behaviour was observed in the case of the MFCs inoculated with effluent whereby the maximum power output 
was observed on day $30\left(33.25 \mathrm{~mW} \cdot \mathrm{m}^{-2}\right.$ anode $\left.-0.99 \mathrm{~mW}\right)$, after which maximum power decreased to $22.06 \mathrm{~mW} \cdot \mathrm{m}^{-2}$ anode $(0.66 \mathrm{~mW})$, and remained stable until the end of the experiment. These results are in line with the electrochemical characterisation of the anode displayed in Figure 4 where it is noticeable that the anode in MFCs inoculated either with stored urine or effluent show the best performance on day 30 (see Figure 4B). These results may be related to the changes observed in the anodic microbial community from day 30 , which showed a significant shift in bacterial community structure.

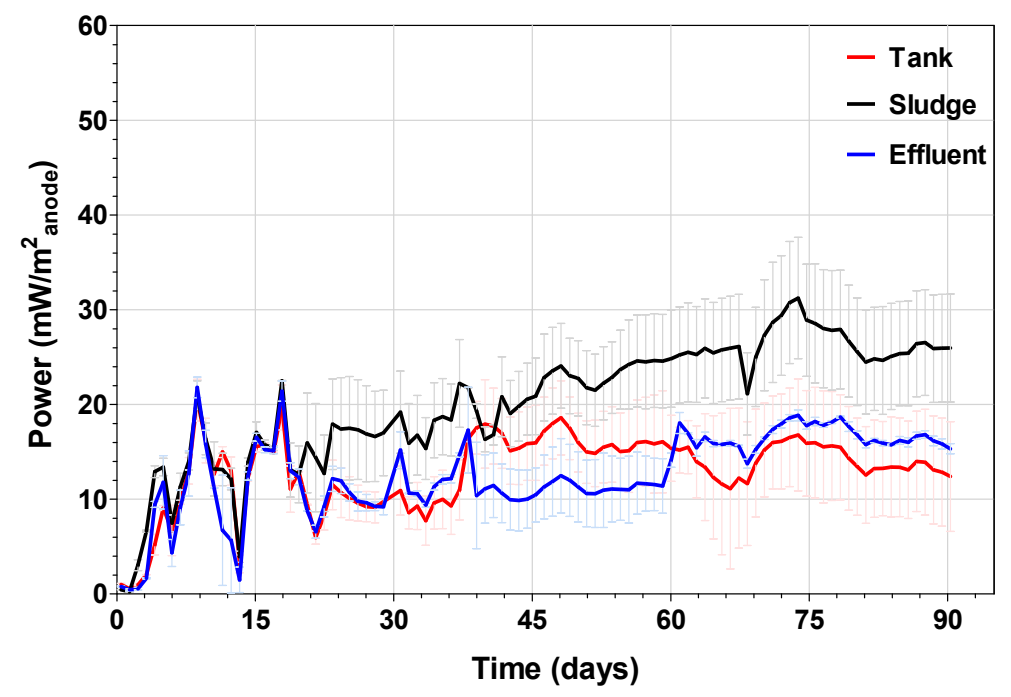

Figure 2. Long-term power performance of the MFCs.
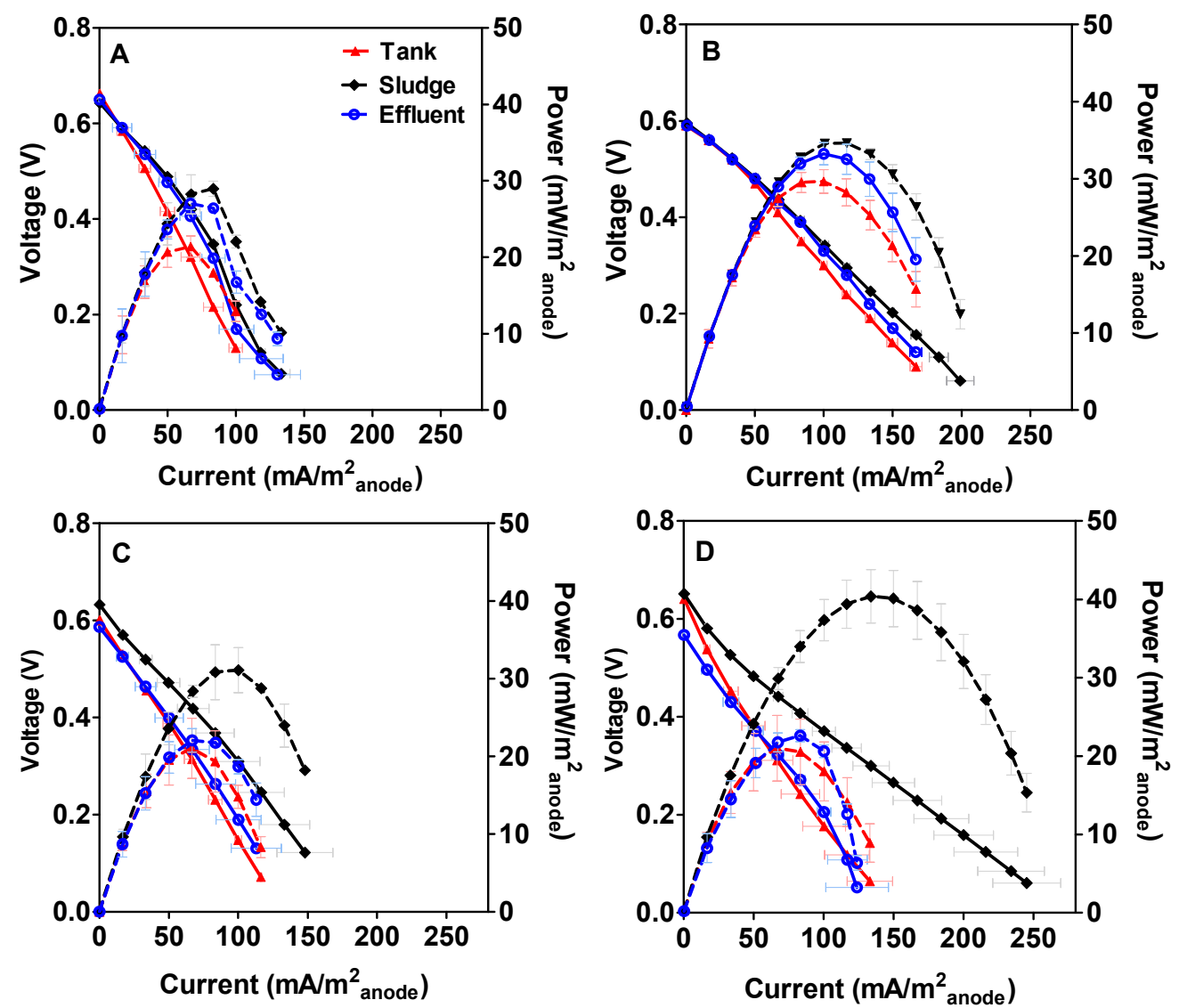

Figure 3. Polarisation and power curves (dashed line) of MFCs inoculated with the different methods after 15 (A), 30 (B), 60 (C) and 90 days (D). 

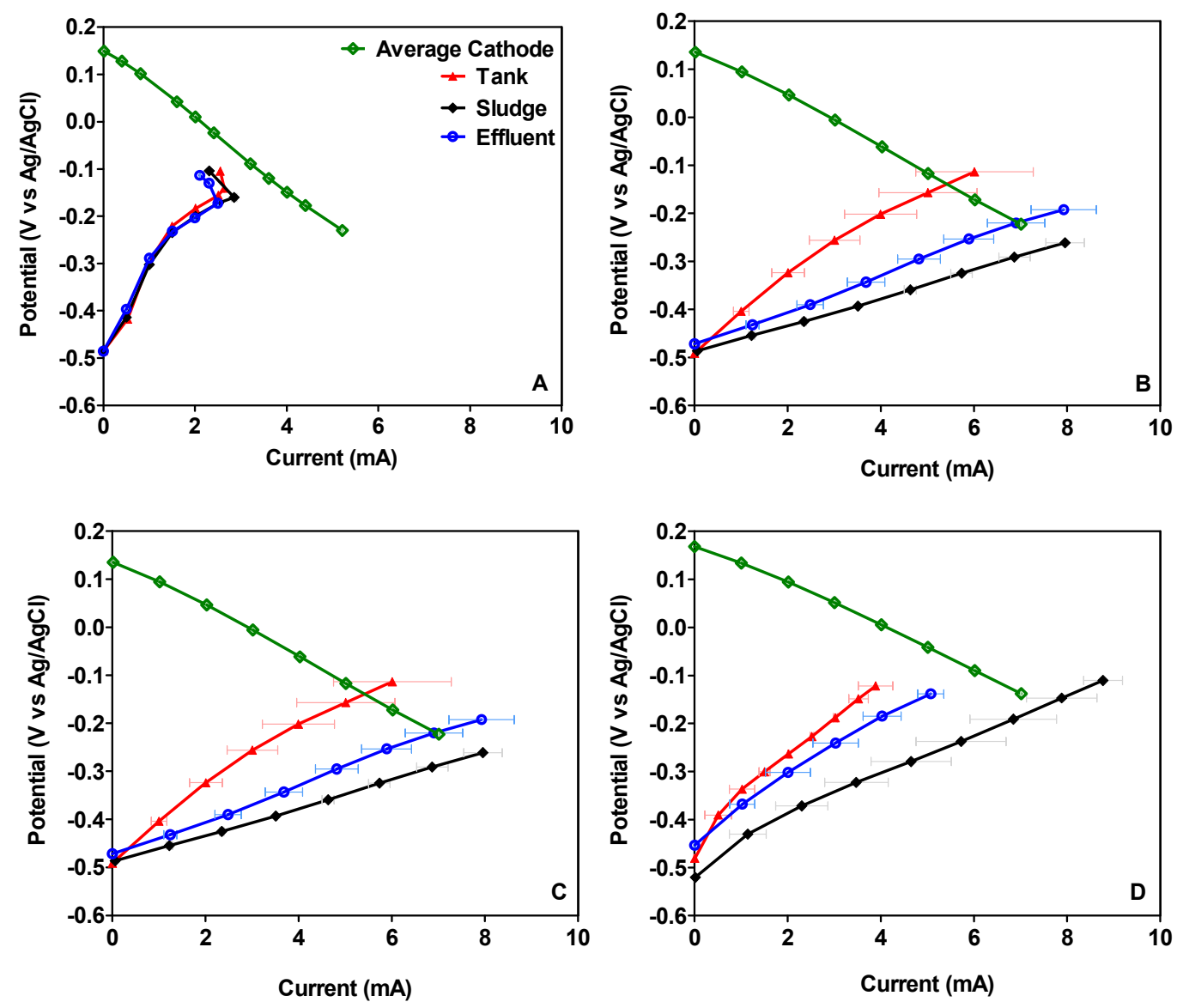

Figure 4. Electrode polarisation of the MFCs after 15 (A), 30 (B), 60 (C) and 90 (D) days.

Table 1 summarises the maximum power output reached by the MFCs inoculated with the different sources over time. The statistical analysis of the results (data not shown) demonstrates that the nature of the different inocula investigated has a significant effect on the power output $(p<0.05)$. As can be seen in Table 1, power output by the sludge-inoculated MFCs greatly increased over time, reaching the highest value after 90 days of operation. By contrast, the maximum power performance of the rest of the conditions investigated is lower, reaching a plateau after 60 days of operation.

Table 1. Summary of the maximum power output by the MFC over time.

\begin{tabular}{cccc}
\hline & \multicolumn{3}{c}{ Maximum Power Output $\left(\mathbf{m W} / \mathbf{m}^{2}\right.$ anode $)$} \\
\hline Time (Days) & Stored Urine & Sludge & Effluent \\
\hline 15 & $21.40 \pm 2.5$ & $28.95 \pm 2.8$ & $27.00 \pm 3.5$ \\
30 & $29.64 \pm 2.3$ & $34.63 \pm 1.9$ & $33.25 \pm 2.8$ \\
60 & $21.04 \pm 3.9$ & $31.11 \pm 3.5$ & $22.06 \pm 2.1$ \\
90 & $21.01 \pm 4.2$ & $40.38 \pm 3.7$ & $22.61 \pm 2.3$ \\
\hline
\end{tabular}

\subsection{Microbial Ecology and Phyla Distribution}

Analysis of the bacteria community at the phylum level showed that Firmicutes strains were dominant within the bacterial community of the stored urine at the start of the experiment (T0). This dominance was observed up until day 30, where they account for about $90 \%$ of the bacterial community (Figure 5A). However, by day 60, the proportion of Firmicutes reduced to ca. $63 \%$ as the proportion of Proteobacteria increased (from only 10\% at T0 and day 30) to approximately $36 \%$. By day 90, Proteobacteria dominated, making up 54\% of the population whilst the proportion of Firmicutes decreased to $45 \%$ (Figure 5A). These results highlight a gradual redistribution of the anodic 
communities, which perhaps is a response to the various biochemical reactions occurring within the MFC reactors over time.
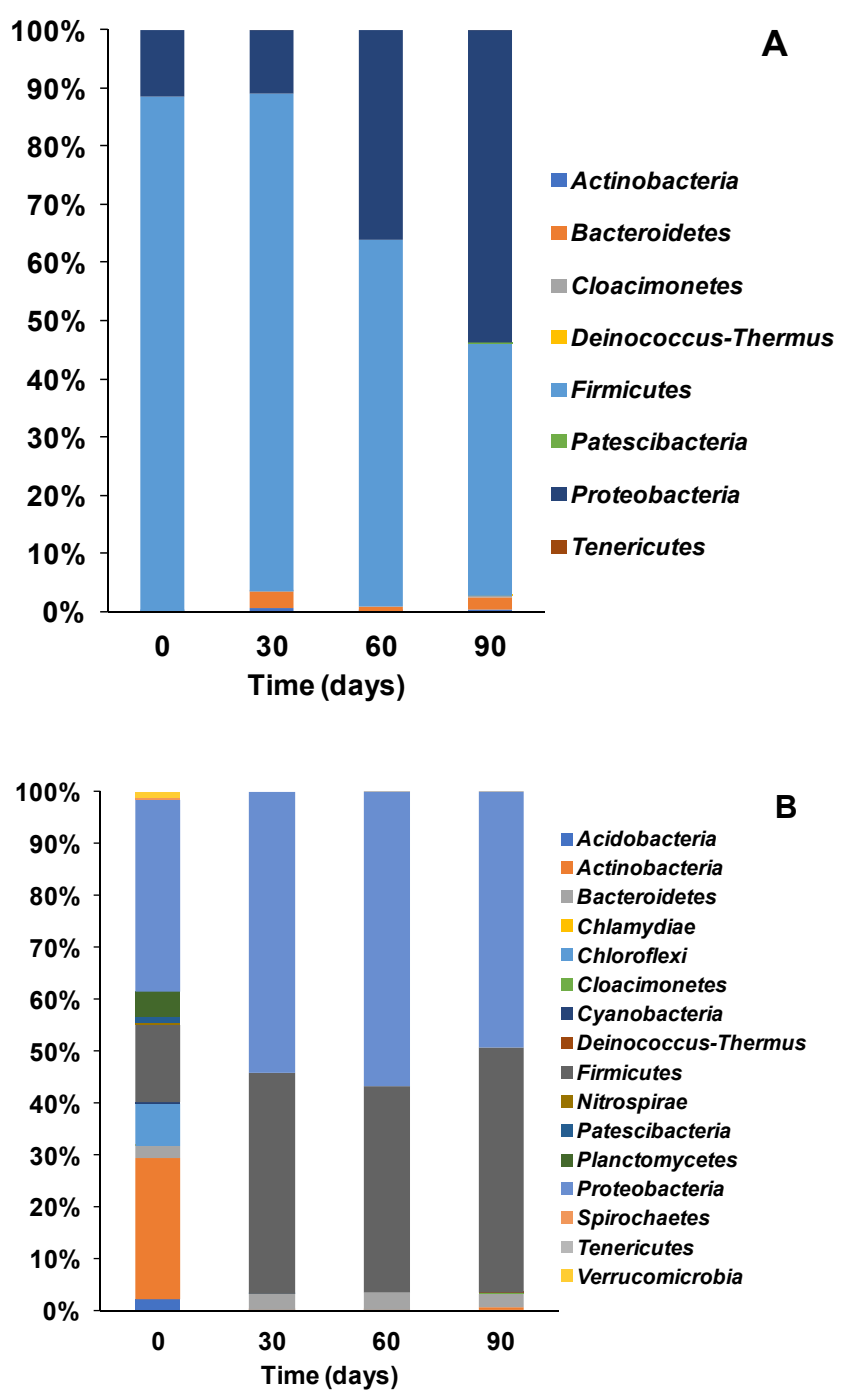

Acidobacteria

Actinobacteria

Bacteroidetes

Chlamydiae

Chloroflexi

Cloacimonetes

- Cyanobacteria

Deinococcus-Thermus

- Firmicutes

Nitrospirae

- Patescibacteria

- Planctomycetes

- Proteobacteria

Spirochaetes

Tenericutes

Verrucomicrobia

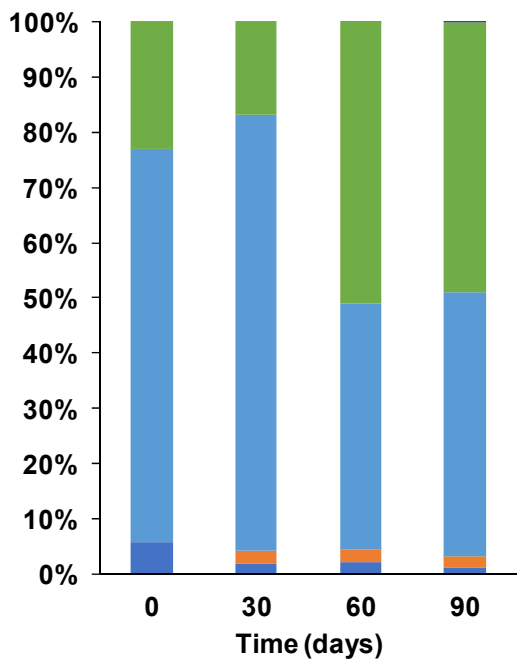

C

Actinobacteria

Bacteroidetes

Cloacimonetes

Deinococcus-Thermus

Firmicutes

Proteobacteria

- Tenericutes

Figure 5. Phyla distribution of the microbial community detected in the stored urine (A), sludge (B) and MFC effluent (C) used as inocula (according to the different methods described earlier). 
For the sludge inoculated reactors, analysis at the phyla level revealed a diverse community at the start of the experiment, which was dominated by Proteobacteria (37\%) and Actinobacteria (27\%). By day 30, there was a significant shift in the community structure and with a concomitant decline in diversity resulting in the detection of only 3 main strains namely Proteobacteria (54\%), Firmicutes $(43 \%)$ and Bacteriodetes (3\%), compared to more than 10 different phyla at T0. There was also the intriguing disappearance of Actinobacteria which constituted $27 \%$ of the community at T0. The shifts in the community structure observed, resulted in the dominance of Proteobacteria and Firmicutes strains from day 30 till the end of the experiment at day 90 (see Figure 5B).

Analysis of the bacterial community of effluents obtained from working MFCs, revealed less diversity at the phyla level compared to the sludge sample. At the start of the experiment T0, only 3 strains were detected, namely Firmicutes (71\%) Proteobacteria (23\%) and Actinobacteria (6\%) (see Figure 5C). By day 30, the proportion of Firmicutes increased to $79 \%$ whilst Protoebacteria decreased to $17 \%$, followed by the detection of the phylum Bacteriodetes, whilst the proportion of Actinobacteria remained stable. However, by day 60 the proportion of Proteobacteria increased to 51\% making it the most dominant strain until the end of the experiment (49\%). The earlier stages of the experiment (T0-T30) saw the dominance of Firmicutes while the latter stages (T60-T90) were dominated by Protoebacteria. This shift in community composition is similar to the results obtained from other inoculation experiments described earlier (see Figure 5).

In general, the results showed a gradual trend of community redistribution leading to a shift of dominance from Firmicutes to Proteobacteria. This observation suggests that members of Firmicutes which were the dominant strains at T0-T30 in all inocula, were important to the various hydrolytic processes at the earlier stages of the experiment. Whereas members of the phylum Proteobacteria, especially for the latter stages (T60-T90) of the experiment, were important for the various biochemical reactions responsible for current generation, in all set ups.

Earlier research has shown the dominance of the two phyla (Protoebacteria and Firmicutes) in MFC systems whether at pilot scale used for the treatment of sewage [44] or operated at lower temperatures [45]. Firmicutes have been previously detected as the dominant strain in glucose fed MFCs, where they are thought to convert carbon into simpler molecules. Being aero-tolerant, Firmicutes have been known for scavenging oxygen, thus providing an enabling environment for facultative anaerobic power producers in MFC [46]. A more recent study reported that members of Firmicutes such as Clostridium are able to reduce insoluble iron and generate electricity [47], an indication of their importance in MFCs.

Proteobacteria on the other hand have been detected in many different microbial fuel cell systems including urine fed MFC [48] and MFCs fed with acetate, butyrate and glucose (amongst many other substrates) [49]. Essentially, many of the prominent known electroactive bacteria such as Shewanella Pseudomonas and Geobacter etc. belong to the phylum Proteobacteria [36,50,51], hence their increased enrichment over time within MFCs (see Figure 5).

\subsection{Bacterial Composition of Community at Genera Level with Different Inoculations}

\subsubsection{Bacterial Community Structure and Genus Distribution in Stored Urine Inoculated MFC Reactors}

Analysis of the bacterial community of the stored urine inoculated reactors at family and genus levels highlighted diverse communities within the MFC anode. At the start of the process, the community was dominated by Aerococcaceae (76\%) belonging to the phylum Firmicutes while Atopostipes and Oligela made up $12 \%$ and $10 \%$ respectively (see Figure $6 \mathrm{~A}$ ). The dominant Aerococcaceae are non-motile, non-spore forming Gram-positive bacteria, which inhabit humans, households and hospital environments [52]. Aerococcaceae contain important members including Aerococcus urinae which is commonly found in human urine and have been associated with some urinary tract infections [53]. 
A

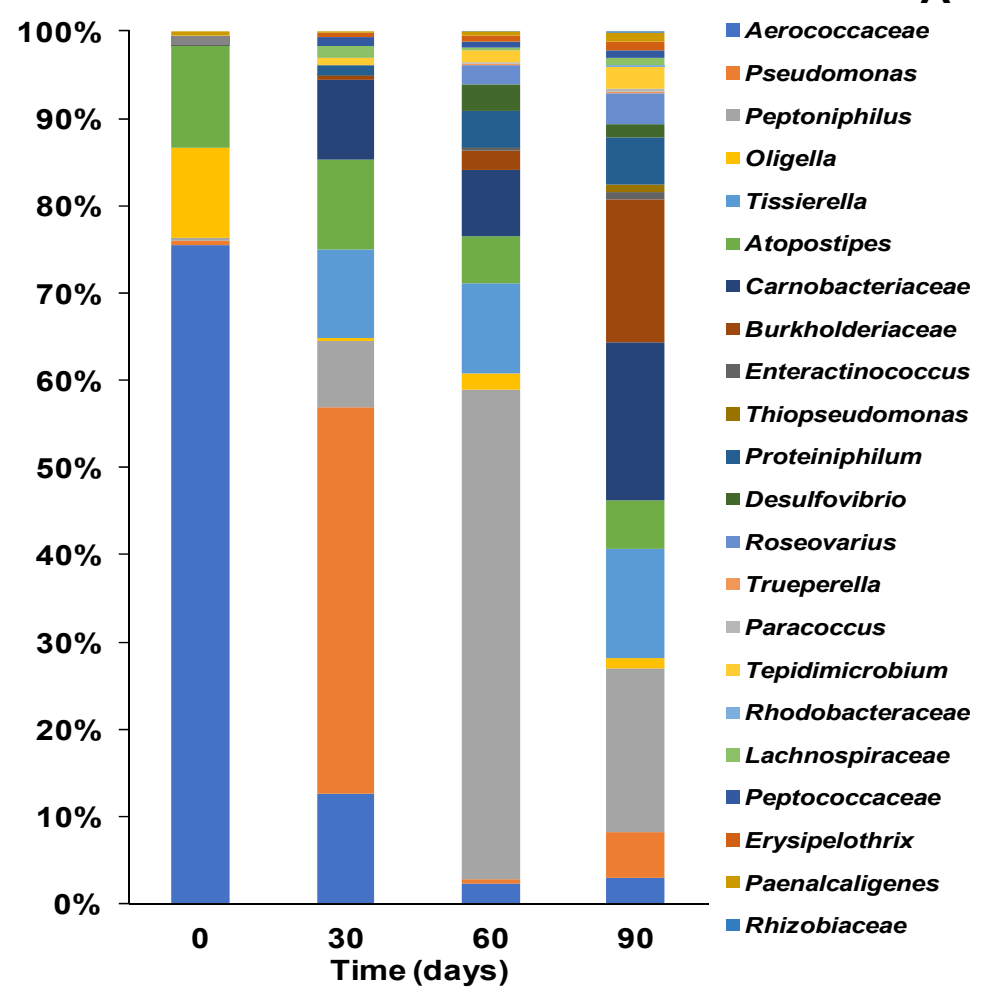

B

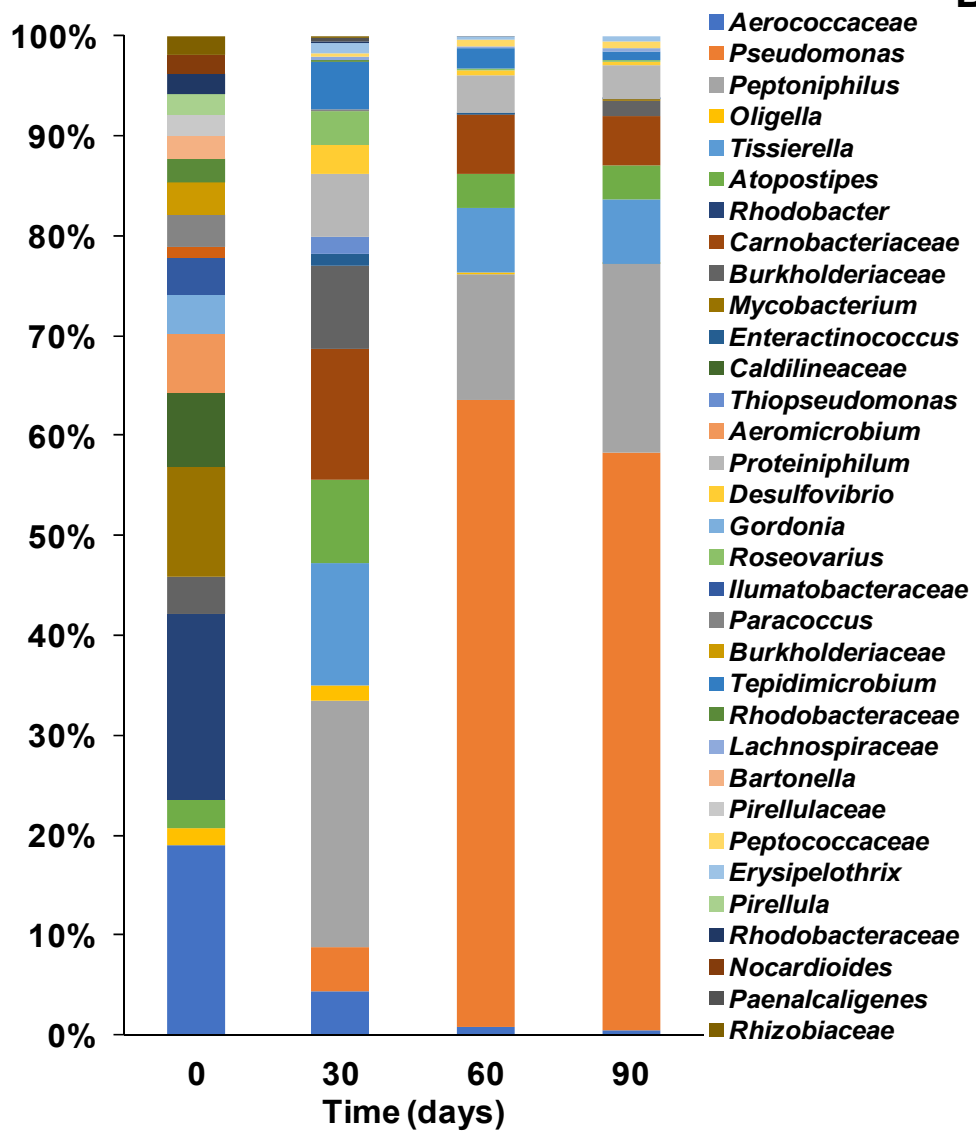

Figure 6. Cont. 


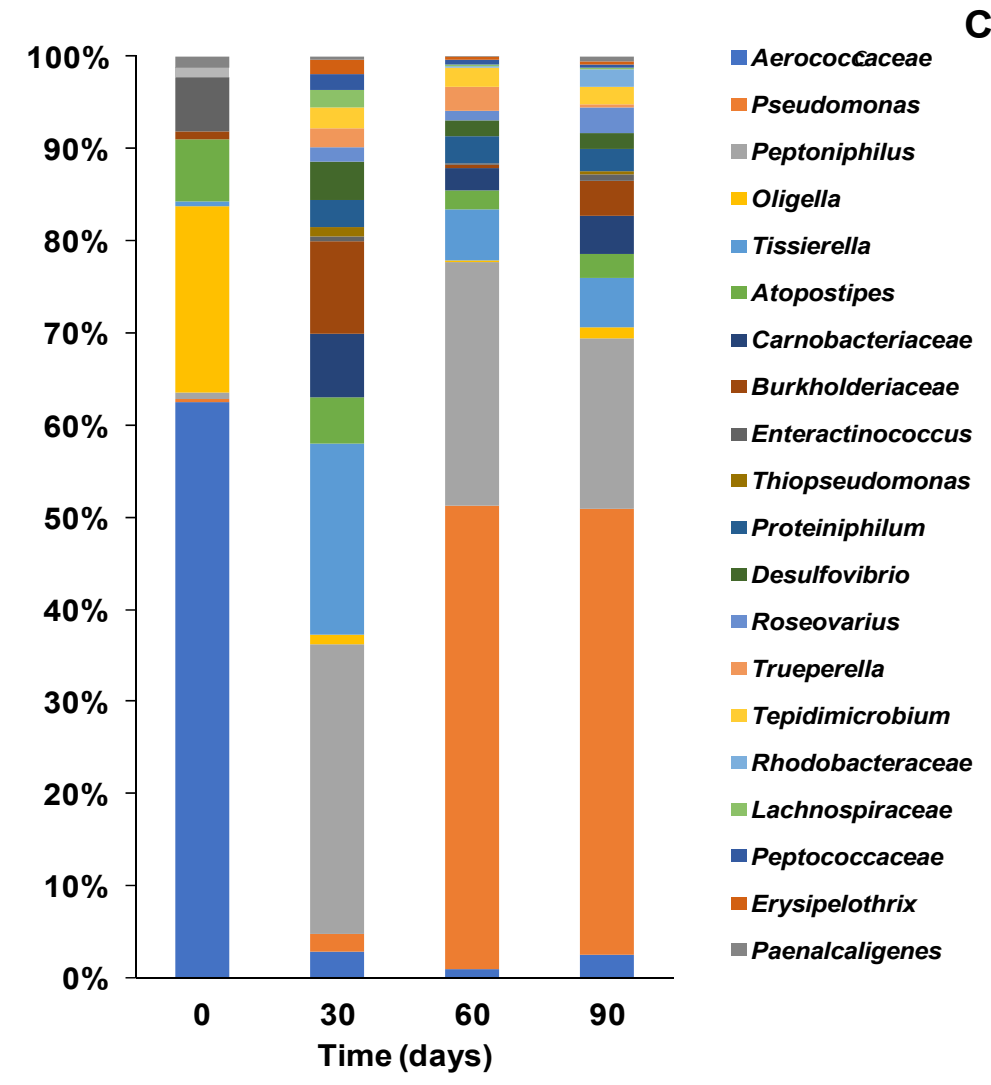

Figure 6. Family and genus distribution of the microbial community detected in the (A), sludge (B) and effluent (C) used to inoculate the MFCs according to the different methods described above.

By day 30, there was a shift in the community composition and distribution, resulting in greater diversity. For instance, members of the genus Tissierella, which was below detection at the start of the process accounted for $10 \%$ of the community while Pseudomonas (which was less than $1 \%$ at T0), became the dominant species accounting for $44 \%$ of the community. Conversely Aerococcaceae which accounted for $76 \%$ of the population reduced to only $13 \%$ by day 30 while Atopostipes, Tissierella, Carnobacteriaceae and Peptoniphilus made up 10\%, 10\%, 9\% and $8 \%$ respectively.

Pseudomonas strains carry out processes using oxidative phosphorylation, a process that enhances current generation in MFCs. Pseudomonas species also utilise pyocyanin and phenazine as mediators for electron transfer in MFCs [54].

Between day 30 and 60, a further shift in the community composition was observed with Peptoniphilus which previously was only at about $8 \%$ becoming the most dominant and accounting for $56 \%$ of the community composition. Moreover, the proportion of Tissierella and Carnobacteriaceae remained largely stable during the process. By day 90 , there were many prominent strains without a single dominant strain within the community. Some of the prominent strains at day 90 include Peptoniphilus (19\%), Carnobacteriaceae (18\%) Burkholderiaceae (16\%) and Tissierella (13\%). The bacterial community at this time was more diverse than previous time points, owning to adaptation and acclimation. Moreover, several changes occurred within the community resulting in the emergence of new strains and reduction in the proportion of previously dominant strains. For instance, members of the genus Peptoniphilus which were the dominant strains at T60 (56\%), became less dominant at T90 accounting for only $19 \%$ of the population. Burkholderiaceae on the other hand, which constituted less than $1 \%$ of the community at $\mathrm{T} 0$ and $\mathrm{T} 30$, and only $2 \%$ at T60 became very prominent at $\mathrm{T} 90$ accounting for more than $16 \%$ of the community. Some members of Burkholderiaceae such as Rhodoferax sp. and Cupriavidus sp. have been reported to carry out extracellular electron transfer via direct and 
mediated means $[36,55]$, which may explain their increased enrichment over time in the current study as more direct and indirect electron transfer is required for electricity generation.

\subsubsection{Bacteria Community Structure and Genus Distribution in Sludge Inoculated MFC Reactors}

Analysis of the bacterial community of the sludge inoculated MFCs revealed a more diverse community with Aerococcaceae and Rhodobacter accounting for 19\% each respectively at T0 (see Figure 6B). In the first 30 days of the experiment, there was a gradual shift in community distribution resulting in the dominance of the genus Peptoniphilus, which made up $25 \%$ of the community at T30. There was a further shift in community structure resulting in reduced diversity and the dominance of the genus Pseudomonas species at T60 representing $63 \%$ of the population and $58 \%$ at T90. A general trend was observed in the community structure thus, as the proportion of the originally dominant Aerococcaceae and Rhodobacter declined over time, the proportion of Pseudomonas increased (Figure 5B). This shift and redistribution of bacterial strains especially after day 30 is perhaps an indication of a period of extensive bio-electrochemical reactions within the MFCs, corresponding to a stage of significant increase in power generation (Figure 2). Moreover, Pseudomonas species have been known to contribute to current generation via mediators for electron transfer $[44,54]$ in MFCs. Therefore, their sustained enrichment at the latter stages of the experiments in sludge inoculated reactors' significantly enhanced power generation.

\subsubsection{Bacteria Community Structure and Genus Distribution in Effluent Inoculated MFC Reactors}

Figure $6 \mathrm{C}$ shows the bacterial community distribution at the genus level over time in the effluent inoculated MFCs. At the start of the experiment (T0), Aerococcaceae was the dominant strain accounting for $63 \%$ of the community. The genus Oligella was the second most dominant bacteria strain at the stage of the experiment making up just over $20 \%$ of the community (Figure $6 \mathrm{C}$ ). By day 30 , there has been a significant shift in community structure which saw the dominant Aerococcaceae go from $63 \%$ at $\mathrm{T} 0$ to only $3 \%$ at T30. However, Peptoniphilus, which made up only around $1 \%$ at $\mathrm{T} 0$ increased to $32 \%$ at T30 and remained largely stable over time. Tissierella species which was only $1 \%$ of the community at T0 had also increased to $21 \%$ by day 30 . The time when considerable amount of electricity generation occurred in the effluent inoculated MFCs, as shown in Figure 2. Tissierela has been reported as an important organism for urine metabolism, which provides the needed carbon source for electroactive communities in urine fed MFCs $[36,56]$. As the experiment progressed, there was a further shift in the community structure, which resulted in the dominance of the genus Pseudomonas, representing $50 \%$ of the community while Peptoniphilus accounted for $27 \%$ (see Figure $6 \mathrm{C}$ ). The emergence of the dominant Pseudomonas at T60 corresponded to a time of increased power generation in the reactors as shown in Figure 1. This is an indication that the Pseudomonas species aided electricity generation by the secretion of pyocyanin, which acts as an electron mediator in MFCs $[49,57]$. Pyocyanin is a known antimicrobial toxin, which may be the reason for the suppression of some of the other species in the mixed community, especially those that were in competition with P. aeruginosa. A relative stability was observed within the bacterial community as Pseudomonas and Peptoniphilus remained the dominant strains accounting for $48 \%$ and $19 \%$ of the community, respectively.

Overall, Pseudomonas species appear to be highly enriched within all MFC reactors in the current study and this might be due to their important contribution to power generation as electron mediators [44].

The establishment of a microbial community in MFCs is naturally dictated by the inoculum, inoculation process and maturing regime [47,49]. The choice of anolyte and substrate and their composition is one of the most important factors that determine the structure, and composition of the microbial community on the anode [58]. Urine fed MFCs have so far been colonised by certain types of bacteria which are quite different from the more conventional and well-known electroactive species such as Geobacter and Shewanella. Most of the previously reported bacterial communities in urine-fed MFCs were also detected in the current study, including Burkholderiaceae, Tissierella, Pseudomonas, Aerococcaceae, Atopostipes, Peptoniphilus, Oligella, Proteiniphilum and Desulfovibrio among others [36]. There findings suggest that these organisms, although having different metabolic requirements, operate 
in a synergistic manner to bring about urine degradation and electricity generation recorded in urine-fed MFCs.

\section{Conclusions}

The current study highlights the impact of the inoculum type on the microbial anodic community in urine-fed MFCs and consequently, on power performance. To this end, the MFCs were inoculated with stored urine, sludge and effluent from a working MFC and then fed continuously with neat urine (in triplicate). The results were compared in terms of microbial anodic community and power performance, as well as long-term functionality. Among the different conditions tested, the inoculation of MFCs with sludge seems to promote a more electroactive biofilm, which results in higher values of power output. MFCs inoculated with sludge outperformed the rest, reaching a maximum power output of $40.38 \mathrm{~mW} \cdot \mathrm{m}^{-2}$ anode $(1.21 \mathrm{~mW})$. Results of the microbial community analysis begin to shed some light on the synergistic activities of bacterial populations, whilst metabolising a complex substrate such as urine and transferring electrons as part of anaerobic respiration.

Author Contributions: Conceptualisation, methodology, validation and investigation, I.A.I., J.G., M.J.S.-G. and O.O.; software, formal analysis and data curation, M.J.S.-G., O.O., H.K., K.C.; writing-original draft preparation, writing - review and editing, M.J.S.-G., O.O. and I.A.I.; resources, supervision, project administration and funding acquisition, I.A.I. All authors have read and agreed to the published version of the manuscript.

Funding: This research was funded by the UK Engineering and Physical Sciences Research Council (Grant No. EP/I004653/1) and the Bill and Melinda Gates Foundation (Grant No. INV-006499). M.J.S.-G is grateful for the support provided by the Fundación Seneca (Ref. 20372/PD/17).

Acknowledgments: Special thanks to Keith Hewett for his help with the microbial analysis.

Conflicts of Interest: The authors declare no conflict of interest.

\section{References}

1. Stirling, J.L.; Bennetto, H.P.; Delaney, G.M.; Mason, J.R.; Roller, S.D.; Tanaka, K.; Thurston, C.F. Microbial fuel cells. Biochem. Soc. Trans. 1983, 11, 451-453. [CrossRef] [PubMed]

2. Potter, M.C. Electrical Effects Accompanying the Decomposition of Organic Compounds. Proc. R. Soc. B Biol. Sci. 1911, 84, 260-276. [CrossRef]

3. Logan, B.E.; Hamelers, B.; Rozendal, R.; Schröder, U.; Keller, J.; Freguia, S.; Aelterman, P.; Verstraete, W.; Rabaey, K. Microbial fuel cells: Methodology and technology. Environ. Sci. Technol. 2006, 40, 5181-5192. [CrossRef] [PubMed]

4. Hernández-Fernández, F.J.; Pérez De Los Ríos, A.; Salar-García, M.J.; Ortiz-Martínez, V.M.; Lozano-Blanco, L.J.; Godínez, C.; Tomás-Alonso, F.; Quesada-Medina, J. Recent progress and perspectives in microbial fuel cells for bioenergy generation and wastewater treatment. Fuel Process. Technol. 2015, 138, 284-297. [CrossRef]

5. Yahia, S.A.A.; Hamadou, L.; Salar-García, M.J.; Kadri, A.; Ortiz-Martínez, V.M.; Hernández-Fernández, F.J.; de los Rios, A.P.; Benbrahim, N. $\mathrm{TiO}_{2}$ nanotubes as alternative cathode in microbial fuel cells: Effect of annealing treatment on its performance. Appl. Surf. Sci. 2016, 387, 1037-1045. [CrossRef]

6. Touach, N.; Ortiz-Martínez, V.M.; Salar-García, M.J.; Benzaouak, A.; Hernández-Fernández, F.; de Ríos, A.P.; El Mahi, M.; Lotfi, E.M. On the use of ferroelectric material LiNbO3 as novel photocatalyst in wastewater-fed microbial fuel cells. Particuology 2017, 34, 147-155. [CrossRef]

7. Haoyu, E.; Cheng, S.; Scott, K.; Logan, B. Microbial fuel cell performance with non-Pt cathode catalysts. J. Power Sources 2007, 171, 275-281. [CrossRef]

8. Yuan, H.; Hou, Y.; Abu-Reesh, I.M.; Chen, J.; He, Z. Oxygen reduction reaction catalysts used in microbial fuel cells for energy-efficient wastewater treatment: A review. Mater. Horiz. 2016, 3, 382-401. [CrossRef]

9. Guendouz, S.; Salar-García, M.J.; Ortiz-Martínez, V.M.; Zerrouki, A.; Houcine, I.; Ríos, A.P.; Hernández-Fernández, F.J. Electrocodeposition method to synthesize low-cost cathodes based on inert carriers for bioenergy production and wastewater treatment in microbial fuel cells. Environ. Prog. Sustain. Energy 2019, 38, 13083. [CrossRef] 
10. Yang, W.; He, W.; Zhang, F.; Hickner, M.A.; Logan, B.E. Single-Step Fabrication Using a Phase Inversion Method of Poly(vinylidene fluoride) (PVDF) Activated Carbon Air Cathodes for Microbial Fuel Cells. Environ. Sci. Technol. Lett. 2014. [CrossRef]

11. Salar Garcia, M.J.; Santoro, C.; Kodali, M.; Serov, A.; Artyushkova, K.; Atanassov, P.; Ieropoulos, I. Iron-streptomycin derived catalyst for efficient oxygen reduction reaction in ceramic microbial fuel cells operating with urine. J. Power Sources 2019, 425, 50-59. [CrossRef] [PubMed]

12. Gajda, I.; You, J.; Santoro, C.; Greenman, J.; Ieropoulos, I.A. A new method for urine electrofiltration and long term power enhancement using surface modified anodes with activated carbon in ceramic microbial fuel cells. Electrochim. Acta 2020, 353, 136388. [CrossRef] [PubMed]

13. Wang, Y.; Wen, Q.; Chen, Y.; Zheng, H.; Wang, S. Enhanced performance of microbial fuel cell with polyaniline/sodium alginate/carbon brush hydrogel bioanode and removal of COD. Energy 2020, 202, 117780. [CrossRef]

14. Wang, Y.; Wen, Q.; Chen, Y.; Li, W. Conductive polypyrrole-carboxymethyl cellulose-titanium nitride/carbon brush hydrogels as bioanodes for enhanced energy output in microbial fuel cells. Energy 2020, 204, 117942. [CrossRef]

15. Salar-Garcia, M.J.; Montilla, F.; Quijada, C.; Morallon, E.; Ieropoulos, I. Improving the power performance of urine-fed microbial fuel cells using PEDOT-PSS modified anodes. Appl. Energy 2020, 278, 115528. [CrossRef]

16. Li, W.-W.; Sheng, G.-P.; Liu, X.-W.; Yu, H.-Q. Recent advances in the separators for microbial fuel cells. Bioresour. Technol. 2011, 102, 244-252. [CrossRef]

17. Yousefi, V.; Mohebbi-Kalhori, D.; Samimi, A. Ceramic-based microbial fuel cells (MFCs): A review. Int. J. Hydrog. Energy 2017, 42, 1672-1690. [CrossRef]

18. Winfield, J.; Gajda, I.; Greenman, J.; Ieropoulos, I. A review into the use of ceramics in microbial fuel cells. Bioresour. Technol. 2016, 215, 296-303. [CrossRef]

19. Mačiulaitis, R.; Malaiškienè, J. Possibilities to control ceramics properties by changing firing cycles. Constr. Build. Mater. 2009, 23, 226-232. [CrossRef]

20. Ghadge, A.N.; Ghangrekar, M.M. Development of low cost ceramic separator using mineral cation exchanger to enhance performance of microbial fuel cells. Electrochim. Acta 2015, 166, 320-328. [CrossRef]

21. Salar-García, M.J.; Ieropoulos, I. Optimisation of the internal structure of ceramic membranes for electricity production in urine-fed microbial fuel cells. J. Power Sources 2020, 451, 227741. [CrossRef] [PubMed]

22. Pandey, P.; Shinde, V.N.; Deopurkar, R.L.; Kale, S.P.; Patil, S.A.; Pant, D. Recent advances in the use of different substrates in microbial fuel cells toward wastewater treatment and simultaneous energy recovery. Appl. Energy 2016, 168, 706-723. [CrossRef]

23. Zhang, E.; Wang, F.; Zhai, W.; Scott, K.; Wang, X.; Diao, G. Efficient removal of nitrobenzene and concomitant electricity production by single-chamber microbial fuel cells with activated carbon air-cathode. Bioresour. Technol. 2017, 229, 111-118. [CrossRef] [PubMed]

24. Pant, D.; Van Bogaert, G.; Diels, L.; Vanbroekhoven, K. A review of the substrates used in microbial fuel cells (MFCs) for sustainable energy production. Bioresour. Technol. 2010, 101, 1533-1543. [CrossRef]

25. Addi, H.; Mateo-Ramírez, F.; Ortiz-Martínez, V.M.; Salar-García, M.J.; Hernández-Fernández, F.j.; de los Ríos, A.P.; Godínez, C.; Lotfi, E.M.; El Mahi, M.; Blanco, L.J.L. Treatment of mineral oil refinery wastewater in microbial fuel cells using ionic liquid based separators. Appl. Sci. 2018, 8, 438. [CrossRef]

26. Addi, H.; Mateo-Ramírez, F.; Salar-García, M.J.; Ortiz-Martínez, V.M.; Hernández-Fernández, F.j.; de los Ríos, A.P.; Godínez, C.; Lotfi, E.M.; El Mahi, M.; Lozano-Blanco, L.J. Ammonium-Based Polymer Ionic Liquid Membrane for Wastewater Treatment and Bioenergy Production. Chem. Eng. Technol. 2018, 41, 379-384. [CrossRef]

27. Ieropoulos, I.; Greenman, J.; Melhuish, C. Urine utilisation by microbial fuel cells; Energy fuel for the future. Phys. Chem. Chem. Phys. 2012, 14, 94-98. [CrossRef]

28. Ledezma, P.; Kuntke, P.; Buisman, C.J.N.; Keller, J.; Freguia, S. Source-separated urine opens golden opportunities for microbial electrochemical technologies. Trends Biotechnol. 2015, 33, 214-220. [CrossRef]

29. Santoro, C.; Garcia, M.J.S.; Walter, X.A.; You, J.; Theodosiou, P.; Gajda, I.; Obata, O.; Winfield, J.; Greenman, J.; Ieropoulos, I. Urine in Bioelectrochemical Systems: An Overall Review. ChemElectroChem 2020, 7, 1312-1331. [CrossRef]

30. Kuntke, P.; Śmiech, K.M.; Bruning, H.; Zeeman, G.; Saakes, M.; Sleutels, T.H.J.A.; Hamelers, H.V.M.; Buisman, C.J.N. Ammonium recovery and energy production from urine by a microbial fuel cell. Water Res. 2012. [CrossRef] 
31. You, J.; Staddon, C.; Cook, A.; Walker, J.; Boulton, J.; Powell, W.; Ieropoulos, I. Multidimensional Benefits of Improved Sanitation: Evaluating 'PEE POWER®' in Kisoro, Uganda. Int. J. Environ. Res. Public Health 2020, 17, 2175. [CrossRef] [PubMed]

32. Oliveira, V.B.; Simões, M.; Melo, L.F.; Pinto, A.M.F.R. Overview on the developments of microbial fuel cells. Biochem. Eng. J. 2013, 73, 53-64. [CrossRef]

33. Heidrich, E.S.; Dolfing, J.; Wade, M.J.; Sloan, W.T.; Quince, C.; Curtis, T.P. Temperature, inocula and substrate: Contrasting electroactive consortia, diversity and performance in microbial fuel cells. Bioelectrochemistry 2018, 119, 43-50. [CrossRef] [PubMed]

34. Rabaey, K.; Rozendal, R.A. Microbial electrosynthesis-Revisiting the electrical route for microbial production. Nat. Rev. Microbiol. 2010, 8, 706-716. [CrossRef]

35. Zhang, Y.; Min, B.; Huang, L.; Angelidaki, I. Electricity generation and microbial community response to substrate changes in microbial fuel cell. Bioresour. Technol. 2011. [CrossRef]

36. Obata, O.; Salar-Garcia, M.J.; Greenman, J.; Kurt, H.; Chandran, K.; Ieropoulos, I. Development of efficient electroactive biofilm in urine-fed microbial fuel cell cascades for bioelectricity generation. J. Environ. Manag. 2020, 258, 109992. [CrossRef]

37. Rismani-Yazdi, H.; Christy, A.D.; Carver, S.M.; Yu, Z.; Dehority, B.A.; Tuovinen, O.H. Effect of external resistance on bacterial diversity and metabolism in cellulose-fed microbial fuel cells. Bioresour. Technol. 2011. [CrossRef]

38. Sun, Y.; Wei, J.; Liang, P.; Huang, X. Electricity generation and microbial community changes in microbial fuel cells packed with different anodic materials. Bioresour. Technol. 2011. [CrossRef]

39. Gajda, I.; Greenman, J.; Melhuish, C.; Ieropoulos, I. Simultaneous electricity generation and microbially-assisted electrosynthesis in ceramic MFCs. Bioelectrochemistry 2015, 104, 58-64. [CrossRef]

40. Ferris, M.J.; Muyzer, G. Denaturing Gradient Gel Electrophoresis Profiles of 16S rRNA-Defined Populations Inhabiting a Hot Spring Microbial Mat Community. Appl. Environ. Microbiol. 1996, 62, 340-346. [CrossRef]

41. Park, M.; Park, H.; Chandran, K. Molecular and Kinetic Characterization of Planktonic Nitrospira spp. Selectively Enriched from Activated Sludge. Environ. Sci. Technol. 2017, 51, 2720-2728. [CrossRef] [PubMed]

42. Rideout, J.R.; Dillon, M.R.; Bokulich, N.A.; Abnet, C.C.; Gabriel, A.; Ghalith, A.; Alexander, H.; Alm, E.J.; Arumugam, M.; Asnicar, F.; et al. QIIME 2: Reproducible, interactive, scalable, and extensible microbiome data science. PeerJ Prepr. 2018, 6, 1-53.

43. Quast, C.; Pruesse, E.; Yilmaz, P.; Gerken, J.; Schweer, T.; Glo, F.O.; Yarza, P. The SILVA ribosomal RNA gene database project: Improved data processing and web-based tools. Nucleic Acids Res. 2013, 41, 590-596. [CrossRef] [PubMed]

44. Liu, R.; Tursun, H.; Hou, X.; Odey, F.; Li, Y.; Wang, X.; Xie, T. Microbial community dynamics in a pilot-scale MFC-AA/O system treating domestic sewage. Bioresour. Technol. 2017, 241, 439-447. [CrossRef]

45. Mei, X.; Xing, D.; Yang, Y.; Liu, Q.; Zhou, H.; Guo, C.; Ren, N. Adaptation of microbial community of the anode biofilm in microbial fuel cells to temperature. Bioelectrochemistry 2017, 117, 29-33. [CrossRef]

46. Jung, S.; Regan, J.M. Comparison of anode bacterial communities and performance in microbial fuel cells with different electron donors. Appl. Microbiol. Biotechnol. 2007, 77, 393-402. [CrossRef]

47. Park, Y.; Cho, H.; Yu, J.; Min, B.; Kim, H.S.; Kim, B.G.; Lee, T. Response of microbial community structure to pre-acclimation strategies in microbial fuel cells for domestic wastewater treatment. Bioresour. Technol. 2017, 233, 176-183. [CrossRef]

48. Cid, C.A.; Stinchcombe, A.; Ieropoulos, I.; Ho, M.R. Urine microbial fuel cells in a semi-controlled environment for onsite urine pre-treatment and electricity production. J. Power Sources 2018, 400, 441-448. [CrossRef]

49. Chae, K.J.; Choi, M.J.; Lee, J.W.; Kim, K.Y.; Kim, I.S. Effect of different substrates on the performance, bacterial diversity, and bacterial viability in microbial fuel cells. Bioresour. Technol. 2009, 100, 3518-3525. [CrossRef]

50. Suzuki, K.; Kato, Y.; Yui, A.; Yamamoto, S.; Ando, S.; Rubaba, O.; Tashiro, Y.; Futamata, H. Bacterial communities adapted to higher external resistance can reduce the onset potential of anode in microbial fuel cells. J. Biosci. Bioeng. 2018, 125, 565-571. [CrossRef]

51. Paitier, A.; Godain, A.; Lyon, D.; Haddour, N.; Vogel, T.M.; Monier, J.M. Microbial fuel cell anodic microbial population dynamics during MFC start-up. Biosens. Bioelectron. 2017, 92, 357-363. [CrossRef] [PubMed]

52. Pasternak, G.; Greenman, J.; Ieropoulos, I. Comprehensive Study on Ceramic Membranes for Low-Cost Microbial Fuel Cells. ChemSusChem 2016, 9, 88-96. [CrossRef] [PubMed] 
53. Higgins, A.; Garg, T. Inflammation and Infection Aerococcus urinae: An Emerging Cause of Urinary Tract Infection in Older Adults with Multimorbidity and Urologic Cancer. Urol. Case Rep. 2017, 13, $24-25$. [CrossRef] [PubMed]

54. Rabaey, K.; Verstraete, W. Microbial fuel cells: Novel biotechnology for energy generation. Trends Biotechnol. 2005, 23, 291-298. [CrossRef] [PubMed]

55. Sydow, A.; Krieg, T.; Mayer, F.; Schrader, J.; Holtmann, D. Electroactive bacteria-Molecular mechanisms and genetic tools. Appl. Microbiol. Biotechnol. 2014, 98, 8481-8495. [CrossRef]

56. Harrns, C.; Schleicher, A.; Collins, M.D.; Andreesen, J.R. Tissierella creatinophila sp. nov., a Gram- positive, anaerobic, non-spore-f orming, creatinine-f errnent ing organism. Int. J. Syst. Bacteriol. 1998, 48, 983-993. [CrossRef]

57. Rabaey, K.; Rodríguez, J.; Blackall, L.L.; Keller, J.; Gross, P.; Batstone, D.; Verstraete, W.; Nealson, K.H. Microbial ecology meets electrochemistry: Electricity-driven and driving communities. ISME J. 2007, 1, 9-18. [CrossRef]

58. Choudhury, P.; Uday, U.S.P.; Mahata, N.; Nath Tiwari, O.; Narayan Ray, R.; Kanti Bandyopadhyay, T.; Bhunia, B. Performance improvement of microbial fuel cells for waste water treatment along with value addition: A review on past achievements and recent perspectives. Renew. Sustain. Energy Rev. 2017, 79, 372-389. [CrossRef]

Publisher's Note: MDPI stays neutral with regard to jurisdictional claims in published maps and institutional affiliations. 